\title{
The Bond Strength of Universal Adhesives with Different Acidities to Calcium Silicate-Based Materials
}

\author{
Elif Kalyoncuoglu ${ }^{1}$ (D), Cangul Keskin ${ }^{1}$ (D), Duygu Hazal Acar ${ }^{2} \mathbb{B}^{\mathbb{D}}$, Nihan Gonulol ${ }^{3}$ \\ ${ }^{1}$ Ondokuz Mayis University, Faculty of Dentistry, Department of Endodontics, Samsun, Turkey. \\ 2 Private Practice, Istanbul, Turkey. \\ ${ }^{3}$ Ondokuz Mayis University, Faculty of Dentistry, Department of Restorative Dentistry, Samsun, Turkey. \\ Correspondence Author: Elif Kalyoncuoglu \\ E-mail: elif_kalyoncu@hotmail.com
}

Received: 20.05.2020 Accepted: 20.03.2021

\begin{abstract}
Objective: To compare the micro-shear bond strengths of 3 different universal adhesives to 2 different calcium silicate-based materials.

Methods: A hole was prepared in the center of the top surfaces of 60 cylindrical acrylic blocks, and the blocks were randomly divided into 2 groups ( $n=30$ ) according to biomaterial filling; NeoMTA Plus (Avalon Biomed Inc. Bradenton, FL, USA) and ProRoot MTA (Dentsply Tulsa, Tulsa, OK, USA). Biomaterials were prepared according to the manufacturers' instructions. The sample surfaces were flattened after the initial setting, and the samples were incubated for $24 \mathrm{~h}$ at $37^{\circ} \mathrm{C}$. After placing the biomaterials in the prepared holes, the specimens were randomly divided into 3 subgroups ( $n=10$ ) according to adhesive; G-Premio Bond (GC Corp., Tokyo, Japan), All-Bond Universal (Bisco, Inc., Schaumburg, IL, USA) and Single Bond Universal (3M ESPE, St Paul, MN, USA). Adhesives were applied to the specimens and polymerized. A micro-hybrid composite resin (Filtek Z250, 3M ESPE, MN, USA) was then placed on the specimen surfaces and polymerized. Micro-shear bond strengths were tested using a universal testing device (LRX, Lloyd Instruments, Farnham, UK). A Shapiro-Wilk test confirmed normal distribution, and 2-way ANOVA was used for statistical analysis.
\end{abstract}

Results: No significant differences were found in the shear bond strengths of any of the tested adhesives to either of the calcium silicate-based materials ( $p>0.05)$.

Conclusion: The results indicate that the acidity of a universal adhesive does not affect the bond strength of composite resin to calcium silicatebased materials.

Keywords: Calcium Silicate, NeoMTA, ProRoot MTA, Shear Strength, Universal Adhesive

\section{INTRODUCTION}

Vital pulp treatment (VPT) aims to maintain the vitality and health of dental pulp in cases where pulp exposure has occurred due to caries or traumatic injury (1). Several procedures have been developed to protect pulp vitality in permanent teeth. Indirect pulp capping involves the controlled excavation of deep caries to prevent pulpal exposure followed by the application of a biomaterial as a protective layer to maintain pulp vitality. With direct pulp capping, a protective layer of biomaterial is applied directly on exposed pulp tissue, and with pulpotomy, the same procedure is performed after partial amputation of the pulp (2). The biomaterial used in VPT must not only be biocompatible and capable of maintaining pulp vitality, it also needs to adhere to both dentin and restorative material and resist the forces generated during restoration placement and function (3). Calcium hydroxide $(\mathrm{CH})$ has long been accepted as the gold standard; however, the materials has some limitations, such as degradation after acid-etching, insufficient adhesion, high solubility in oral fluids, tunnel defects inside the dentin bridge, and pulp-chamber obliteration caused by excessive dentin formation (4).

Several materials have been proposed as alternatives to $\mathrm{CH}$, including calcium hydroxide liners, dentin bonding agents, mineral trioxide aggregate, glass ionomer cement, zinc oxide/eugenol, calcium silicate, and medical Portland cement (5). Mineral Trioxide Aggregate (MTA), comprised of bismuth oxide and modified Portland cement, was developed as a durable, biocompatible alternative for use in various endodontic applications (6). Over the years, studies have shown that MTA can be used successfully in pulpotomy procedures, pulp capping, apexification and root-canal obturation as well as for treating perforations and internal root resorption $(6,7)$. In addition to biocompatibility, MTA possesses low solubility, is able to set in wet conditions and in the presence of blood, and can prevent bacterial leakage; 
however, the material is difficult to manipulate and has a long setting time (8).

The bond strength between the pulp-capping and restorative materials plays a very important role in restoration quality (9). Some studies have suggested that restoration with a resin composite and a bonding agent can be performed immediately following MTA placement. Moreover, acidetching prior to composite application has been shown to produce surface changes that increase the bond strength of resin-based materials; however, it has also been shown to reduce the compressive strength and surface microhardness of MTA $(10,11)$. Recently, universal adhesives (UAs) have been introduced that can be used in either etch\&rinse, selfetching, or selective-etching modes, depending upon clinical conditions and the clinician's preferences. These new, singlebottle adhesives have become popular due to their simple application procedures and short application times (12). These adhesive systems differ from etch-and-rinse adhesives in several aspects, such as the initial pH, type of acidic monomer, the concentration of water and solvents, and the hydrophilicity of the bonding layer and they can be classified as mild, moderate and acidic systems depending on their initial $\mathrm{pH}$ (13). Previous studies have stated that the bond strength of MTA to resin can be affected by adhesive solvent type (acetone, ethanol, or water) and filler content (10); however, the effect of UA acidity on the bond strength of MTA to resin composite has not been investigated. Therefore, this study aimed to compare the micro-shear bond strength of three diferrent UAs with different acidity levels (G-Premio Bond-1,5 (14), Single Bond Universal-2,7 (15) and All-Bond Universal-3,2 (16) to ProRoot MTA and NeoMTA Plus. The null hypothesis was that there would be no difference in the micro-shear bond strength of UAs with different acidity levels to the calcium silicate-based biomaterials tested.

\section{METHODS}

Ethics committee approval was not taken due to in vitro design of the study. This study does not include human participants. Thus, no consent form was required. Sample size was calculated a priori using the effect size of a previous study (17) with analysis of variance (fixed effects, omnibus, 1-way) test from $\mathrm{F}$ test family and an alpha-type error of 0.05 and a power beta of 0.95 (G*Power 3.1 for Mac.; Heinrich Heine, Universitat Dusseldorf, Dusseldorf, Germany). Ten specimens per group were indicated as the minimum sample size to observe the same effect.

Material composition and manufacturer details are given in Table 1. A 5-mm dia. x 2-mm h. hole was prepared in the centre of the top surfaces of 60 cylindrical acrylic blocks, which were then randomly divided into 2 groups $(n=30)$ according to biomaterial filling. NeoMTA Plus (Avalon Biomed Inc. Bradenton, FL, USA) and ProRoot MTA (Dentsply Tulsa, Tulsa, OK, USA) were prepared according to the manufacturers' instructions by mixing the ProRoot MTA powder with the liquid provided and the NeoMTA Plus powder with the anti-washout gel provided. The materials were transferred into the holes and compacted using a spatula. The samples were covered with wet cotton pellets, stored at $37^{\circ} \mathrm{C}$ and $100 \%$ humidity for 24 hours to allow the materials to set completely, and then polished with 600-grit SiC paper (\#600, Tigre; Pinceis Tigre SA, Castro, Brazil) for 60 seconds to obtain uniform, flat surfaces.

Table 1. The chemical compositions and manufacturer details of the tested materials

\begin{tabular}{|c|c|c|}
\hline Material & Main components & Manufacturer \\
\hline $\begin{array}{l}\text { ProRoot }{ }^{\mathbb{R}} \text { Mineral } \\
\text { Trioxide Aggregates }\end{array}$ & $\begin{array}{l}\text { Tricalcium silicate, } \\
\text { bismuth oxide, } \\
\text { dicalcium silicate, } \\
\text { tricalcium aluminate, } \\
\text { calcium sulfate } \\
\text { dehydrate or gypsum }\end{array}$ & $\begin{array}{l}\text { Dentsply Tulsa Dental, } \\
\text { OK, USA }\end{array}$ \\
\hline NeoMTA Plus & $\begin{array}{l}\text { Powder: Tricalcium } \\
\text { silicate }\left(\mathrm{Ca}_{3} \mathrm{SiO}_{5}\right) \text {, } \\
\text { Dicalcium silicate } \\
\left(\mathrm{Ca}_{2} \mathrm{SiO}_{4}\right) \text {, and } \\
\text { Tantalum oxide }\left(\mathrm{Ta}_{2} \mathrm{O}_{5}\right) \text {. } \\
\text { Liquid: Water }\left(\mathrm{H}_{2} \mathrm{O}\right) \\
\text { and proprietary } \\
\text { polymers. }\end{array}$ & $\begin{array}{l}\text { Avalon Biomed, } \\
\text { Bradenton, Florida }\end{array}$ \\
\hline G-Premio Bond & $\begin{array}{l}\text { MDP, 4-MET, MEPS, } \\
\text { methacrylate } \\
\text { monomer, acetone, } \\
\text { water, initiator, silica } \\
\text { filler,pH:1,5 }\end{array}$ & GC, Tokyo, Japan \\
\hline Single Bond Universal & $\begin{array}{l}\text { MDP, Bis-GMA, HEMA, } \\
\text { DMA, methacrylate } \\
\text { functional copolymer, } \\
\text { filler, ethanol, water, } \\
\text { initiators, silane } \\
\text { pH:2,7 }\end{array}$ & $\begin{array}{l}\text { 3M ESPE, St Paul, MN, } \\
\text { USA }\end{array}$ \\
\hline All-Bond Universal & $\begin{array}{l}\text { MDP, Bis-GMA, } \\
\text { HEMA, ethanol, water, } \\
\text { initiators } \\
\mathrm{pH}: 3,2\end{array}$ & $\begin{array}{l}\text { Bisco Inc, Schaumburg, } \\
\text { IL, USA }\end{array}$ \\
\hline $\begin{array}{l}\text { Filtek Z250 Universal } \\
\text { Restorative System }\end{array}$ & $\begin{array}{l}\text { Zirconia/silica filler, } \\
\text { UDMA, Bis-GMA and } \\
\text { Bis-EMA resins. }\end{array}$ & 3M ESPE,MN, USA \\
\hline
\end{tabular}

Bis-GMA: bisphenol-A-glycidyldimethacrylate; Bis-EMA: ethoxylated bisphenol-A-dimethacrylate; $\quad M D P$ : 10-methacryloyloxydecyl dihydrogen phosphate; HEMA: 2-hydroxyethyl methacrylate; 4-MET: 4-methacryloyloxyethyl trimellitate; MEPS: methacryloyloxyalkyl thiophosphate methylmethacrylate; UDMA: urethane dimethacrylate; DMA: N, N-dimethylacrylamide.

Specimens were then randomly divided into 3 subgroups according to universal adhesive $(n=10)$. G-Premio Bond (GC Corp., Tokyo, Japan), All-Bond Universal (Bisco, Inc., Schaumburg, IL, USA) and Single Bond Universal (3M ESPE, St Paul, MN, USA) were applied according to the manufacturers' instructions and polymerized with a LED light-curing unit (Elipar S100, 3M ESPE, MN, USA) for $10 \mathrm{~s}$. A silicone tube (0.8 $\mathrm{mm}$ internal dia. $\mathrm{x} 2 \mathrm{~mm} \mathrm{~h}$.) was positioned on the centre of each sample, and composite resin (Filtek Z250, 3M ESPE,MN, USA) was placed inside the tubes and polymerized for 20 
seconds. Specimens were stored at $37^{\circ} \mathrm{C}$ and $100 \%$ humidity for 24 hours.

Micro-shear bond strength was tested using a knife-edge blade mounted in a Universal Testing Device (LRX, Lloyd Instruments, Farnham, UK) (Figure 1). A load was applied with a crosshead speed of $1 \mathrm{~mm} / \mathrm{min}$., and the load at failure was recorded in Newtons and converted into MPa. Failure modes were evaluated by a single operator under a stereomicroscope (Nikon SMZ 745T; Tokyo, Japan) at x40 magnification and categorized as either mainly adhesive, mainly cohesive within the resin cement, or mixed (Figure 2).

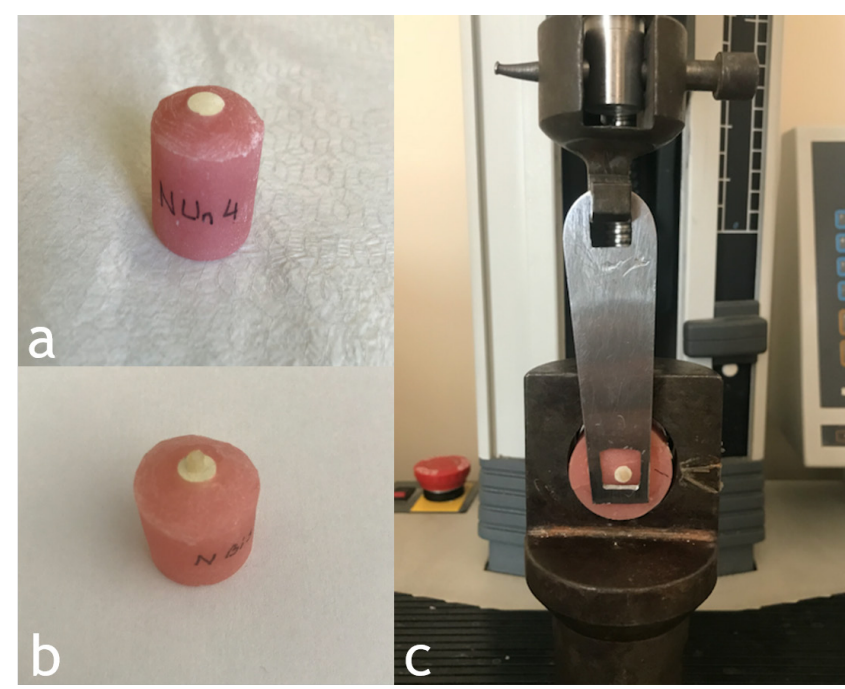

Figure 1. a) Preparation of the samples, b) sample bonded with composite material, c)The universal testing machine

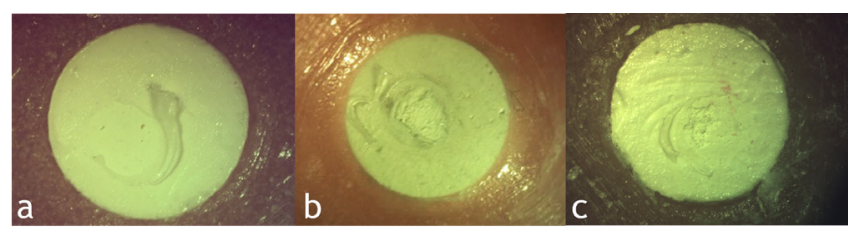

Figure 2. Images of fractured samples showing: a) Adhesive failure in resin composite bonded to NeoMTA Plus b) Cohesive failure of resin composite bonded to ProRoot MTA c) Mixed failure in ProRoot MTA.

\subsection{Statistically analysis}

A Shapiro-Wilk test confirmed a normal distribution of data. Micro-shear bond-strength data were statistically analyzed using two-way analysis of variance, and a chi-square test was used to analyse the distribution of failure modes. Statistical analysis was performed with the software SPSS v.21.0 (IBM, SPSS Inc., Chicago, IL, U.S.A.) with the level of significance set at $5 \%$.

\section{RESULTS}

Mean micro-shear bond strength values and standard deviations of the groups are given in Table 2. No significant differences were observed in the micro-shear bond strengths of any of the adhesives tested to either NeoMTA Plus or ProRoot MTA $(p>0.05)$. Moreover, all the tested adhesives showed similar bond-strengths to both of the calcium silicatebased biomaterials tested ( $p>0.05$ ). Failure modes are given in Table 3. The majority of failures in the ProRoot MTA subgroups were cohesive failures, whereas both adhesive and cohesive failures were observed in the NeoMTA Plus subgroups.

Table 2. Mean Shear Bond Strength Values $(\mathrm{MPa})$ and Standard Deviations of Each Groups ( $n=10)$. Different superscript lower case letters in each row and capital letters in each column indicate indicate statistically significant differences $(P<0,05)$

\begin{tabular}{|l|c|c|c|}
\hline & NeoMTA Plus & ProRoot MTA & N \\
\hline G-Premio & $3.58 \pm 0.64^{\mathrm{aA}}$ & $3.35 \pm 0.53^{\mathrm{aA}}$ & 10 \\
\hline $\begin{array}{l}\text { All-Bond } \\
\text { Universal }\end{array}$ & $2.71 \pm 1.15^{\mathrm{aA}}$ & $3.09 \pm 0.81^{\mathrm{aA}}$ & 10 \\
\hline $\begin{array}{l}\text { Single Bond } \\
\text { Universal }\end{array}$ & $3.75 \pm 1.12^{\mathrm{aA}}$ & $3.11 \pm 0.41^{\mathrm{aA}}$ & 10 \\
\hline
\end{tabular}

Table 3. Distribution of Failure Modes within Groups $(n=10)$

\begin{tabular}{|c|c|c|c|c|}
\hline \multirow{5}{*}{ NeoMTA Plus } & Adhesive & Cohesive & Mixed \\
\cline { 2 - 5 } & $\begin{array}{c}\text { G-Premio } \\
\text { All-Bond } \\
\text { Universal }\end{array}$ & 4 & 4 & 2 \\
\cline { 2 - 5 } & $\begin{array}{c}\text { Single Bond } \\
\text { Universal }\end{array}$ & 2 & 2 & 3 \\
\hline \multirow{3}{*}{ ProRoot MTA } & G-Premio & - & 6 & 4 \\
\cline { 2 - 5 } & $\begin{array}{c}\text { All-Bond } \\
\text { Universal }\end{array}$ & 2 & 2 & 6 \\
\cline { 2 - 5 } & $\begin{array}{c}\text { Single Bond } \\
\text { Universal }\end{array}$ & 2 & 7 & 1 \\
\hline
\end{tabular}

\section{DISCUSSION}

The hypothesis of this study was accepted, because there was no difference in the micro-shear bond strength of UAs with different acidity levels to the calcium silicate-based biomaterials tested.

ProRoot MTA is the most commonly used and most studied brand of endodontic repair material and is used in surgical as well as non-surgical procedures. Composed mainly of tricalcium silicate (53.1\%), dicalcium silicate (22.5\%), bismuth oxide $(21.6 \%)$, with small amounts of tricalcium aluminate and calcium sulfate (18), its thin, hydrophilic particles cure in a humid environment at $12.5 \mathrm{pH}$ over a period of 3-4 hours (19). NeoMTA Plus is a new material composed of finely powdered tricalcium silicate that incorporates tantalum oxide $\left(\mathrm{Ta}_{2} \mathrm{O}_{5}\right)$ rather than bismuth oxide as a radiopacifying agent to prevent discoloration and is mixed with a water-based gel to impart good processing properties (20). By changing the powder-gel ratio, NeoMTA Plus can be used in a variety of 
applications, with a thin mixture used in orthograde filling and a thicker mixture used in retrograde filling. According to the manufacturer, NeoMTA Plus can be used in vital pulp treatment (for pulp capping, pulpotomy, and as a cavity liner/base), root apexification, root repair (resorption and perforation), root-end filling, and root-canal sealing (21).

The adhesive properties of restorative materials are most commonly evaluated according to bond-strength, assessment of which has become a well-recognized method of analyzing material performance in vitro. In this study, the adhesive properties of tricalcium silicate-based materials and universal adhesives were evaluated by measuring shear bond strengths (10).

Due to its hydrophilic properties, ProRoot MTA requires moisture to initiate setting (22). For this reason, the application of a damp cotton pellet for 3-4 hours is recommended in order to supplement tissue fluids and provide two-sided hydration during perforation repair and pulp capping (6). A previous study reported this method to provide optimal results with a $24 \mathrm{~h}$ application, whereas double-hydration of ProRoot MTA for 72 hours resulted in a significant reduction in bond strength that the authors attributed to the potential negative impact of excessive humidity and possible solubility of the material (23). Therefore, in the present study, MTA was stored in $100 \%$ humidity for $24 \mathrm{~h}$ before bonding.

In order to simplify application procedures and reduce technical errors, one-step self-etch adhesives have been developed. Studies have noted that the acidic monomers used in self-etch adhesives play a key role in their enamel and dentin bonding performance (24). Generally, self-etch adhesives are classified as either "strong" $(\mathrm{pH}<1)$, "intermediately strong" $(\mathrm{pH} \approx 1.5)$, "mild" ( $\mathrm{pH} \approx 2)$ and "ultra-mild" $(\mathrm{pH} \geq 2.5)$ (25), with the $\mathrm{pH}$ value known to strongly affect the solubility of the smear layer and the depth of demineralization of underlying dentin $(26,27)$. Considering the differences in $\mathrm{pH}$ of the adhesives used in this study (G-Premio Bond: 1.5; Single Bond Universal:2.7; All-Bond Universal:3.2), the degree of biomaterial dissolution was expected to vary. Previous studies have stated that micromechanical retention and therefore bond strength increases with increases in surface porosity of tricalcium silicate based cements $(28,29)$. Phosphoric acid etching has been suggested to provide greater microretention and potentially increases the bonding effectiveness of resinous materials by significantly enhancing the surface energy of substrate material (10). Moreover, Yelamali et al. have reported two-step etch-and-rinse and two-step self-etching primer systems to perform significantly better than an all-in-one adhesive system in terms of bond strength when bonding composite resin to white MTA (30). In contrast to these findings, the present study indicated differences in acidity among universal adhesives to have no significant effect on shear bond strentgh values, suggesting that microretention is not noticeably improved by lowering the acidity of self-etch adhesives.

Although the adhesives tested vary according to $\mathrm{pH}$, they all contain the monomer 10-MDP, whose binding mechanism to dentin has been explored in a previous study. According to the authors, when an adhesive containing MDP is rubbed onto dentin, the surface is partially demineralized up to a submicron depth, and the MDP reacts with the released $\mathrm{Ca}$ ions to create nano-layers of MDP-Ca salts within the hybrid layer (31). In light of this earlier finding, it may be suggested that the bonds between the adhesives tested in the present study and both ProRoot MTA and NeoMTA are strengthened by chemical chelation of the $\mathrm{Ca}$ ions contained in these tricalcium silicate-based biomaterials (1).

However, despite the interaction between the MDP monomer and the calcium ions, the bond strengths of the adhesives to the tested cements were considerably lower than the threshold values of 17-20 MPa that are reportedly required to sufficiently resist contraction forces and produce gap-free restoration margins $(32,33)$. It is likely that the bond between the cement and adhesives could be increased by using the same UAs in etch\&rinse mode to increase porosity of the resin cement, thereby improving microretention.

With regard to fracture modes, according to Tate et al. (34) a bond is considered to be acceptable when fracture occurs within a material rather than at the bonded interface, i.e. when the fracture is cohesive rather than adhesive. In the present study, cohesive fracture predominated in the ProRoot MTA group.

\section{CONCLUSION}

The findings of the present study showed that the acidity of universal adhesives has no effect on the bond strength of tricalcium silicate-based biomaterials to restorative materials.

Acknowlegment: The study was presented at the 8th International Symposium of Turkish Endodontic Society, 1013 May 2018, Adana, Turkey

\section{REFERENCES}

[1] Gandolfi MG, Spagnuolo G, Siboni F, Procino A, Rivieccio V, Pelliccioni GA. Calcium silicate/calcium phosphate biphasic cements for vital pulp therapy: chemical - physical properties and human pulp cells response. Clin Oral Invest 2015; 19: 2075-2089.

[2] Bjorndal L, Demant S, Dabelsteen S. Depth and activity of carious lesions as indicators for the regenerative potential of dental pulp after intervention. J Endod 2014; 40: 76-81.

[3] Cohen BD, Combe EC. Development of new adhesive pulp capping materials. Dent Update 1994; 21: 57-62.

[4] Brizuela C, Ormeño A, Cabrera C, Cabezas R, Silva Cl, Ramirez V. Direct Pulp Capping with Calcium Hydroxide, Mineral Trioxide Aggregate and Biodentine in Permanent Young Teeth with Caries: A Randomized Clinical Trial. J Endod 2017; 43: 17761780.

[5] Santos PSD, Pedrotti D, Braga MM, Rocha RDO, Lenzi TL. Materials used for indirect pulp treatment in primary teeth: a mixed treatment comparisons meta-analysis. Braz Oral Res 2017; 31: e101. 
[6] Torabinejad M, Chivian N. Clinical applications of mineral trioxide aggregate. J Endod 1999; 25: 197-205.

[7] Ford TR, Torabinejad M, Abedi HR, Bakland LK, Kariyawasam SP. Using mineral trioxide aggregate as a pulp capping material. J Am Dent Assoc 1996; 127: 1491-1494.

[8] Altunsoy M, Tanriver M, Ok E, Kucukyilmaz E. Shear bond strength of a self-adhering flowable composite and a flowable base composite to mineral trioxide aggregate, calciumenriched mixture cement, and Biodentine. J Endod 2015; 41: 1691-1695.

[9] Tunc ES, Sonmez IS, Bayrak S, Eğilmez T. The evaluation of bond strength of a com - posite and a compomer to white mineral trioxide aggregate with two different bonding systems. J Endod 2008; 34: 603-605.

[10] Tyagi N, Chaman C, Tyagi SP, Singh UP, Sharma A. The shear bond strength of MTA with three different types of adhesive systems: An in vitro study. J Conserv Dent 2016; 19: 130-133.

[11] Kayahan MB, Nekoofar MH, Kazandağ M, Canpolat C, Malkondu O, Kaptan F. Effect of acid-etching procedure on selected physical properties of mineral trioxide aggregate. Int Endod J 2009; 42: 1004-1014.

[12] Shafiei F, Mohammadparast P, Jowkar Z. Adhesion performance of a universal adhesive in the root canal: Effect of etch-andrinse vs. self-etch mode. PloS one 2018; 13: e0195367.

[13] Moura SK, Reis A, Pelizzaro A, Dal-Bianco K, Loguercio AD, Arana-Chavez VE. Bond strength and morphology of enamel using self-etching adhesive systems with different acidities. J Appl Oral Sci 2009; 17: 315-325.

[14] https://www.gcamerica.com/products/operatory/G-Premio_ BOND

[15] https://www.3m.com.tr/3M/tr_TR/turkiye-tr/tum-urunler/ / Single-Bond-Universal-Adeziv-5-ml

[16] https://www.bisco.com/assets/1/22/All_Bond_Universal_ Brochure2.pdf

[17] Neves TDC, Presoto CD, Wajngarten D, Campos EA. Microshear bond strength of adhesives with different degrees of acidity: Effect on sound and artificially hypermineralized dentin. Microsc Res Tech 2020; 83: 393-401.

[18] Camilleri J. Characterization of hydration products of mineral trioxide aggregate. Int Endod J 2008; 41: 408-417.

[19] Torabinejad M, Smith PW, Kettering JD, Ford TRP. Comparative investigation of marginal adaptation of mineral trioxide aggregate and other commonly used root-end filling materials. J Endod 1995; 21: 295-299.

[20] Camilleri J. Staining potential of Neo MTA Plus, MTA Plus and Biodentine used for pulpotomy procedures. J Endod 2015; 41: 1139-1145.
[21] Siboni F, Taddei P, Prati C, Gandolfi MG. Properties of NeoMTA Plus and MTA Plus cements for endodontics. Int Endod J 2017; 50: 83-94.

[22] Lee SJ, Monsef M, Torabinejad M. Sealing ability of a mineral trioxide aggregate for repair of lateral root perforations. J Endod 1993; 19: 541-544.

[23] Walker MP, Diliberto A, Lee C. Effect of setting conditions on mineral trioxide aggregate flexural strength. J Endod 2006; 32: 334-336.

[24] Fujita-Nakajima K, Aoki-Tabei N, Arita A, Nishiyama N. NMR study on the demineralization mechanism of the enamel and dentin surfaces in MDP-based all-in-one adhesive. Dent Mater 2018; 2017-2292.

[25] Van Meerbeek B, De Munck J, Yoshida Y, Inoue S, Vargas M, Vijay P. Adhesion to enamel and dentin: currents status and future challenges. Oper Dent 2003; 28: 215-235.

[26] De Munck J, Van Landuyt K, Peumans M, Poitevin A, Lambrechts $P$, Braem M. A critical review of the durability of adhesion to tooth tissue: methods and results. J Dent Res 2005; 84: 118132.

[27] De Munck J, Vargas M, Iracki J, Van Landuyt K, Poitevin A, Lambrechts $P$. One-day bonding effectiveness of new self-etch adhesives to bur-cut enamel and dentin. Oper Dent 2005; 30 : 39-49.

[28] Ginebra MP, Fernandez E, Driessens FC, Planell JA. Modeling of the hydrolysis of $\alpha$-tricalcium phosphate. J Amer Ceram Soc 1999; 82: 2808-2812.

[29] Spagnuolo G, D’Antò V, Valletta R, Strisciuglio C, Schmalz G, Schweikl H. Effect of 2-hydroxyethyl methacrylate on human pulp cell survival pathways ERK and AKT. J Endod 2008; 34: 684-688.

[30] Yelamali S, Patil AC. Evaluation of shear bond strength of a composite resin to white mineral trioxide aggregate with three different bonding systems-An in vitro analysis. J Clin Exp Dent 2016; 8: $273-277$.

[31] Yoshida Y, Yoshihara K, Nagaoka N, Hayakawa S, Torii Y, Ogawa T. Self-assembled nano-layering at the adhesive interface. J Dent Res 2012; 91: 376-381.

[32] Davidson CL, de Gee AJ, Feilzer A. The competition between the composite-dentin bond strength and the polymerization contraction stress. J Dent Res 1984; 63: 1396-1399.

[33] Al-Sarheed MA. Evaluation of shear bond strength and SEM observation of all-in-one self-etching primer used for bonding of fissure sealants. J Contemp Dent Pract 2006; 7: 9-16.

[34] Tate WH, Friedl KH, Powers JM. Bond strength of composites to hybrid ionomers. Oper Dent 1996; 21: 147-152. 